\title{
TEORIA CRÍTICA E A GESTÃO SOCIAL DA EDUCAÇÃO: REFLEXÓES A PARTIR DA TEORIA DO AGIR COMUNICATIVO DE HABERMAS*
}

\section{Darlan Marcelo Delgado** Luiz Roberto Gomes**}

\begin{abstract}
Resumo: O objetivo do artigo é apresentar o conceito de gestão social, fundado na Teoria do Agir Comunicativo de Habermas, como forma de reflexão crítica sobre a Administração Educacional Tradicional. Vislumbram-se possibilidades em se pensar uma concepção de administração educacional voltada à formação plena, de sujeitos autônomos e emancipados, preparados para o trabalho, para a vida e para a ação política esclarecida.
\end{abstract}

Palavras-chave: Teoria Crítica da Sociedade; Jürgen Habermas; Teoria do Agir Comunicativo; Educação Profissional; Administração Educacional.

Resúmen: Este artículo trata del concepto de gestión social basado en la Teoría de La Acción Comunicativa de Habermas como una reflexión crítica de la gestión educativa tradicional. Vislumbranse posibilidades en pensar una concepción de administración educativa capaz de proporcionar una formación plena, de sujetos autónomos y emancipados, preparados para la vida, para el trabajo y también acción política esclarecida.

Palabras claves: Teoría Crítica de la Sociedad; Jürgen Habermas; Teoría de la Acción Comunicativa; Educación Profesional; Administración Educativa.

\section{Introdução}

O presente artigo aborda o tema da Administração da Educação ${ }^{1}$, sua

\footnotetext{
* O presente artigo é uma versão ainda embrionária da abordagem nele proposta, a qual foi complementada e adensada no artigo intitulado "Habermas e a Gestão Social: perspectivas para uma administração educacional crítica", submetido ao periódico Education Policy Analysis Archives, Arizona State University.

${ }^{* *}$ Professor Permanente do Programa de Mestrado Profissional em Gestão e Desenvolvimento da Educação Profissional - Unidade de Pós-Graduação, Extensão e Pesquisa e da Faculdade de Tecnologia de Mococa - Ceeteps. E-mail: darlan.delgado@cps.sp.gov.br

*** Professor Associado do Departamento de Educação - DEd e Professor Permanente do Programa de Pós-graduação em Educação - PPGE da Universidade Federal de São Carlos - UFSCar. Email: luizrgomes@ufscar.br
}

\begin{abstract}
1 Empregamos a expressão "Administração da Educação" para nos referir ao campo de estudos formalmente denominado pelo Conselho Nacional de Desenvolvimento Científico e Tecnológico (CNPq) na divisão de áreas do conhecimento e por fazer uma contraposição à Administração tradicional (burocrática). Os termos administração e gestão têm sido empregados de modo bastante diverso na literatura $e$ na nomenclatura de entidades de classe no campo da Educação, tanto em função dos momentos históricos, quanto em relação às conotações e concepções que carregam. Há extensa literatura sobre a definição e emprego desses termos, como em Cury (2002) e Sander (2005). Uma breve explicação sobre a recente preponderância do emprego de "gestão" é oferecida por Sander (2005, p. 124): "O certo é que o termo gestão vem-se impondo crescentemente no pensamento administrativo do setor público e da educação brasileira. É consagrado na Constituição de 1988, na Lei de Diretrizes e Bases da Educação Nacional de 1996 e em numerosos instrumentos normativos dos sistemas de ensino do país".
\end{abstract}

DELGADO, Darlan Marcelo; GOMES, Luiz Roberto. Teoria Crítica e a gestão social da educação: reflexões a partir da teoria do agir comunicativo de Habermas. Revista Sul-Americana de Filosofia e Educação. Número 29: nov./2017-abr./ 2018, p. 37-55. DOI: https://doi.org/10.26512/resafe.v0i29.21005 
articulação com a Política Educacional e os respectivos fundamentos filosóficos norteadores. A inquietação intelectual que deu ensejo à reflexão ora apresentada reside na possibilidade de pensar uma plausível concepção de Gestão Educacional Crítica, particularmente no âmbito da Educação Profissional como escopo de interesse. Com isso pretendemos expressar não apenas a busca por uma crítica imanente da concepção tradicional de organização e gestão (burocrática, em sentido weberiano) de sistemas e unidades escolares, como também a tentativa de esboçar uma alternativa, a qual tem seus fundamentos na Teoria Crítica da Sociedade.

O campo de conhecimento da Administração da Educação foi sendo construído historicamente a partir da mimetização das sucessivas escolas de Administração de empresas ao longo da evolução do próprio pensamento administrativo $e$ isso foi se cristalizando na gestão educacional a ponto de esta ser intensamente dependente do conjunto de saberes e práticas da administração que se faz no mundo empresarial, orientada pela racionalidade econômica que lhe dá suporte.
Partimos da premissa de que o processo educacional que se faz na escola é distinto da produção de bens e da prestação de serviços que ocorre no mercado e no mundo empresarial. A escola é espaço social de formação humana em todas as suas dimensões, indo além de conteúdos curriculares que podem ser transmitidos $e$ apreendidos, mesmo considerando-se a Educação Profissional. A educação envolve aspectos culturais e simbólicos, estéticos, emocionais, morais, políticos e, inclusive, econômicos, mas não se restringindo apenas a este último. Ao adotar esta premissa e partir da hipótese de que a escola é uma organização sui generis por formar o humano, então seria plausível colocar a Administração tradicional (burocrática, empresarial) aplicada à escola em estado de suspeição, buscar uma crítica imanente desta forma de administrar $e$ engendrar uma concepção alternativa de Administração Educacional para a escola $e$ para os sistemas escolares. $\mathrm{O}$ ponto de partida dessa seara localiza-se na concepção de "gestão social".

Dado que o conceito de "gestão social" é elaborado a partir da Teoria do Agir Comunicativo de Habermas e que a própria linha de pesquisa do qual esse conceito deriva é constituída 
majoritariamente pela orientação da Teoria Crítica da Sociedade, incluindo autores da primeira geração, o objetivo central do artigo é buscar elementos teóricos e esboçar categorias de análise preliminares que possam subsidiar a formulação de uma concepção crítica de Administração da Educação, tomando-se da Teoria Crítica a inspiração necessária ao embasamento filosófico norteador de uma perspectiva de gestão educacional emancipatória. Como os próprios autores da área da Administração consideram esse um campo ainda em gestação, e, partindo-se da premissa defendida por Benno Sander de que a Administração da Educação é e deve ser um campo teórico e praxiológico específico $e$ independente, torna-se legítimo $e$ salutar buscar compreender e, se possível, incorporar os avanços alcançados pela teoria das organizações, a partir da teoria crítica, à administração e organização educacional.

Com o intuito de realizar essa discussão, o artigo foi dividido em quatro seções. Além desta breve introdução, que pretendeu indicar ao leitor a problematização e abordagem do tema, na próxima seção apresentaremos algumas considerações sobre a relação da Administração da Educação com a
Administração tradicional ou empresarial, resgatando alguns elementos históricos relevantes da constituição de ambas; posteriormente, na seção seguinte introduziremos algumas noções sobre a concepção de "gestão social" vis-à-vis às colocações de Jürgen Habermas em relação à Teoria do Agir Comunicativo (TAC) e as possibilidades daí resultantes sobre a abordagem da relação entre trabalhociência/técnica-educação. Ainda nessa seção apresentaremos uma agenda de pesquisa a partir desse ponto de vista da aplicação da TAC de Habermas à administração ou gestão educacional. Por fim, com o objetivo de concluir o ensaio, apresentaremos ao leitor algumas breves considerações finais.

\section{A colonização da educação pelo sistema}

As ações no sentido de organizar e controlar as ações humanas na condução das atividades de produção de bens $e$ produtos para atender às necessidades dos povos, seja nas tribos, por meio das seitas religiosas, de agremiações ou ajuntamentos, corporações militares e outras instituições são milenares, contudo a "gerência", enquanto fenômeno organizacional sistematizado, aplicado de modo normativo 
e prescritivo e, portanto, transformado em corpo de saber técnico passível de ser transmitido, ou seja, ensinado ${ }^{2}$ e estudado por meio da "ciência" (ciência positivista) é um fenômeno do século XIX, resultante do crescimento das necessidades organizacionais derivadas da Revolução Industrial (SANDER, 2005; KUENZER ZUNG, 1984; WEBER, 1958). Isso significa dizer que o modo de controle sistematizado, regrado e apoiado em bases científicas é um fenômeno histórico resultante da passagem do modo artesanal feudal (pré-capitalista) ao modo industrial de produção (capitalista).

Três pontos fundamentais sofrem mudanças nessa transição do feudalismo ao capitalismo industrial, a saber: a passagem do trabalho escravo ou cativo ao trabalho assalariado, a irrupção da necessidade de perene desenvolvimento tecnológico ante um mundo artesanal marcado pela tradição e pelas respectivas tecnologias estacionárias e, finalmente, a dinâmica de acumulação de capital (reinvestimentos e expectativas de

\footnotetext{
2 Max Weber deixa isso claro no ensaio intitulado "Burocracia", como se pode ler no seguinte excerto: "Office manegement, at least all specializd office management - and such management is distinctly modern - usually pressupposes thorough and expert training." (WEBER, 1958, p. 198). Ainda quanto à relação entre educação (exames e diplomas) e burocracia recomenda-se a leitura do ensaio "The Chinese Literati", na mesma obra.
}

lucro) diante da ausência da "racionalidade calculadora", como nomeia Max Weber em Historia económica general (WEBER, 2001). Essa conjuntura implica na necessidade do controle do trabalhador assalariado $e$, portanto, da produtividade do fator trabalho, assim como também sobre a maximização do uso de recursos (naturais, de matérias-primas e insumos, além de capital produtivo) no processo de produção, ou seja, sobre a eficiência econômica do fator terra e do fator capital. Tecnologia, desse ponto de vista argumentativo, pode ser entendida tanto como o conjunto de saberes técnicos de coordenação da força de trabalho quanto de aplicações do "como fazer" das rotinas de produção, além de também significar o conjunto de aparatos técnicos propriamente resultantes dessa dinâmica.

Ritmo de trabalho e velocidade de produção passam a ser imprescindíveis, revelando a magnitude da importância da variável tempo ${ }^{3}$ revolucionada pelo modo

\footnotetext{
3 No ensaio intitulado "Burocracia", assim se expressa Max Weber quanto à relação entre velocidade das operações e a administração: "Today, it is primarily the capitalist market economy wich demands that the official business of the administration be discharged precisely, unambiguously, continuously, and with as much speed as possible. Normally, the very large, modern capitalist enterprises are themselves unequalled models of strict bureaucratic organization. Business manegement throughout restes on increasing
} 
de produção capitalista. Não é por outro motivo que a manifestação pioneira da "administração" na forma da "gerência científica" de Frederick Taylor se concentre exatamente no controle dos movimentos corporais do trabalhador, nos seus gestos mais simples nas ações de execução da atividade laboral. A importância da figura de Taylor às formas de organização do trabalho tem profundo significado como suporte ao tipo de acumulação capitalista que se realizou ao longo de boa parte do século XX. A própria pessoa de Taylor expressa muito do conteúdo de sua obra como proponente de uma burocracia administrativa sui generis ao capitalismo industrial. Segundo expõe Tragtenberg (2006) ele é de uma família de quakers, o que the proporcionou uma educação na observação estrita do trabalho, disciplina $e$ poupança, afastando-se da frivolidade mundana. Ainda sobre os aspectos pessoais de Taylor que ultrapassam o limite de sua vida particular e cristalizam-se na sua gerência, podemos ler em Braverman (1980, p. 87):

Em sua constituição psíquica Taylor era um exemplo exagerado de personalidade obsessiva-compulsiva: desde a mocidade ele contava seus passos, media o tempo de

precision, steadiness, and, above all, the speed of operations" (WEBER, 1958, p. 215. grifo nosso). suas várias atividades e analisava seus movimentos à procura de 'eficiência'. [...] $\mathrm{O}$ retrato de sua personalidade [...] justifica chamá-lo, no mínimo, de maníaconeurótico. Esses traços ajustam-se a ele perfeitamente por seu papel como profeta da moderna gerência capitalista, visto que o que é neurótico no indivíduo, no capitalismo é normal e socialmente desejável para o funcionamento da sociedade.

O taylorismo e a ciência do início do século $\mathrm{XX}$ transformam as formas de organização do trabalho, como aponta Vargas (1985, p. 158)

[...] o Taylorismo recebeu a influência da penetração da ciência na indústria sob uma perspectiva positivista. Esta característica ficou marcada não só pela preocupação ideológica de assumir um caráter de neutralidade pela legitimação científica ('Scientific Management'), mas também como uma real preocupação de utilizar o conhecimento, formalizado até então, para controlar a força de trabalho.

Segundo explica Tragtenberg (2006), a pedra angular do sistema de organização e controle $e^{4}$ do trabalho de Taylor reside no estudo do tempo e na cronometragem das atividades executadas pelos trabalhadores. Para Maurício Tragtenberg o método originalmente desenvolvido por Taylor não seria propriamente a racionalização do trabalho, mas sim sua intensificação, até porque ele

\footnotetext{
4 "O controle foi o aspecto essencial de gerência através da sua história, mas com Taylor ele adquiriu dimensões sem precedentes." (BRAVERMAN, 1980, p. 86).
} 
se interessou no trabalho pesado (não qualificado) com o uso de pás, o trabalho de fundição, de pedreiro, daí sua preocupação com a fadiga muscular (e seu desconhecimento da fadiga nervosa, a mais sutil). O que era fundamental a ele era a velocidade de execução de atividades pesadas de trabalho, buscando rendimentos máximos e não ótimos. Segundo Tragtenberg (2006), a visão que Taylor tinha do homem era negativa, sendo os indivíduos naturalmente preguiçosos $e$ ineficientes, infantilizados e limitados na capacidade de compreensão. "Com essa visão do homem, ele define o papel monocrático do administrador." (TRAGTENBERG, 2006, p. 94). O autor afirma categoricamente que reside na obra de Taylor uma paideia, ou seja, um ideal de formação humana de um tipo de personalidade, a qual deriva diretamente da lógica e das características intrínsecas ao sistema da sua administração científica do trabalho. Vale destacar que a burocracia não é um tipo de sistema social, mas sim uma forma de exercício de poder, um modelo de dominação, daí a relação entre a necessidade de hierarquias piramidais rígidas, com linha de comando $e$ comunicação monológica, na qual se espera dos comandados a obediência ao cumprimento das normas (WEBER, 1999; WEBER, 1958).

O panorama de fins do século XIX e início do XX contempla a imagem da própria Administração nascente, enquanto forma de conhecimento derivada da realidade econômica do capitalismo industrial que vai se consolidando $e$ direcionando para a Segunda Revolução Industrial. $\mathrm{O}$ chamado padrão de acumulação fordista desse período, tendo como berço os Estados Unidos da América e a fábrica de automóveis da Ford, é construído, do ponto de vista da gestão da força do trabalho, sobre os princípios $e$ técnicas de Frederick Taylor e de sua "gerência científica"

(Scientific

Management). Os princípios que norteiam a gerência científica ou racional do trabalho são três: (i) princípio da dissociação do processo de trabalho das especialidades dos trabalhadores; (ii) princípio da separação entre concepção e execução e (iii) princípio da utilização do monopólio do conhecimento sobre o processo de trabalho e sua execução (RODRIGUES, 1998).

Segundo Sander (2005), na esteira do Taylorismo, ao longo do século XX foram surgindo as demais "teorias de administração", especialmente as de Fayol e de Weber, na França e na Alemanha, 
respectivamente. $\mathrm{O}$ estudo sobre a burocracia conduzido por Max Weber em Economia e sociedade (WEBER, 1999) juntamente com sua apreciação das condições de surgimento do chamado capitalismo moderno em Historia económica general (WEBER, 2001) evidenciam como a racionalidade que ele chamou de calculadora ${ }^{5}$ e que os autores da Escola de Frankfurt nomeariam anos depois de "razão instrumental" foram fundamentais para a concepção de uma noção de administração geral orientada tanto às empresas privadas (administração empresarial) quanto ao Estado (administração pública).

A relação entre teorias administrativas formações socioeconômicas é uma tese definida por Tragtenberg (2006, p. 109), para quem as primeiras "[...] cumprem a função de elemento mediador entre a macrossociedade e a microorganização pelo agente, o administrador". Com essas colocações pode-se entender que as categorias da teoria geral da administração são históricas (TRAGTENBERG, 2006) e

\footnotetext{
${ }^{5} \mathrm{Na}$ tipologia weberiana, assume papel central a ação racional com referência a fins, ação de caráter teleológico que Habermas nomeia de "agir racionalfinalista" e sobre o qual ele explica que as demais ações podem ser niveladas como desvios em relação a essa tipologia (HABERMAS, 2012a, p. 29).
}

relacionam-se dialogicamente com as necessidades de produção e das relações de organização do trabalho e da produção em cada momento do desenvolvimento. Sendo assim, não apenas o Estado passa a estar submetido à razão instrumental do campo técnico de saberes da Administração como todas as demais instituições e organizações sociais, sendo a escola (e o sistema escolar) uma dessas.

Nesse mesmo sentido, como esclarece Sander (2005; 2007), o corpo teórico de saberes técnicos da "escola clássica de administração" e "da escola comportamental dos psicólogos sociais" acabou por estabelecer princípios e modelos de estruturas organizacionais concebidos com a pretensão de guiar a ação de governo não apenas na indústria $e$ nas atividades comerciais, como também aplicadas à Igreja, ao Estado e também às escolas. Apesar de esse autor enfatizar a dinâmica de desdobramentos da administração em campos particulares, o que ele nomeia por "princípio da especificidade" da administração, argumentando sobre o surgimento de uma "administração da educação", de modo semelhante a existência da "administração industrial" (Fayol) e da "administração pública" (Willoughby), ainda assim é 
necessário tornar explícito que a "administração da educação" foi sendo concebida desde suas origens mimetizando a administração empresarial.

Segundo Kuenzer Zung (1984) os primeiros estudos no campo da "administração da educação" ocorreram no início do século XX, nos Estados Unidos, absorvendo as ideias de Taylor, como é o caso citado pela autora no artigo publicado por Bobbit em 1913 sobre o papel do cargo de diretor escolar. A obra de Querino Ribeiro, publicada no Brasil em 1938, sobre o fayolismo aplicado à administração da escola pública pode ser tomado como uma marca emblemática desta colonização da administração educacional pela lógica $e$ especificidades da administração empresarial. Maia (2008) afirma que esse processo de dependência teórico-prática do campo da administração educacional em relação à administração empresarial ocorreria, grosso modo, por dois motivos: i) pela tendência de os teóricos da administração empresarial elaborarem princípios com pretensões universais em termos organizacionais, generalizáveis para todas as organizações, inclusive aquelas cujas finalidades essenciais e objetivos primordiais não são a busca pelo lucro e a acumulação de capital, como é o caso das instituições educacionais; e ii) pelo fato de que a Educação é pressionada por demandas oriundas do setor produtivo da economia, além de ser constrangida, na organização e administração escolar, pelas leis de mercado, ou seja, pela razão instrumental. Por esse motivo, Gruschka (2008) denuncia a existência de uma "sistemática subsunção da Educação à Economia" ao abordar a "cultura como empreendimento". A subordinação do conhecimento (ciência e técnica) à racionalidade econômica, assim como seu processo de instrumentalização, não são temas inéditos, ao contrário, tem sido a temática central abordada pelos intelectuais da Escola de Frankfurt desde a primeira geração, em particular por Adorno, Horkheimer e Marcuse. Com Habermas e suas obras, continua como eixo principal de análise a razão na modernidade e seus desdobramentos, a saber, a crítica da razão instrumental e a busca de uma alternativa a esta, o que ele nomeou de razão comunicativa. Após a publicação de Teoria do agir comunicativo (originalmente em 1981), de Habermas, um número considerável de pesquisadores brasileiros da Administração passou a estudar e empregar esta e outras obras do autor no campo da Teoria das Organizações (TO). Na próxima 
seção, abordaremos as possibilidades inerentes ao conceito de "gestão social", oriundo dessas pesquisas em Administração, para uma possível contribuição à elaboração de uma agenda de pesquisa no campo da Administração da Educação.

\section{A TAC, a gestão social e a proposição de uma Administração Educacional Dialógica}

Em 1990 se iniciam os debates acerca do novo papel a ser exercido pela administração pública no Brasil após as profundas transformações causadas pela onda neoliberal que se irradiou a partir da Europa (da Inglaterra, de Margareth Tatcher), passando aos Estados Unidos (de Ronald Reagan) e chegando e se instalando no Brasil (de Fernando Henrique Cardoso e de sua reforma ministerial, encabeçada pelo então ministro Luiz Carlos Bresser Pereira). Foi nesse momento histórico que Fernando Guilherme Tenório, docente da então Escola Brasileira de Administração Pública, afirma ter dado início ao Programa de Estudos em Gestão Social e, nesse contexto, criado o conceito de "gestão social", uma alternativa à "gestão estratégica" (ou administração burocrática), como uma nova agenda de pesquisa.

Em artigo intitulado Gestão social: reflexões teóricas e conceituais (CANÇADO, TENÓRIO \& PEREIRA, 2011) os autores tornam explícita a insatisfação, por parte dos pesquisadores da área de Administração, com as limitações das teorias organizacionais tradicionais (mainstream), de caráter positivista $e$ funcionalista, e apontam uma intensa busca por alternativas a elas que contemplem as questões de natureza política e cultural presentes nas organizações, o que dependeria de uma perspectiva gerencial dialógica, a busca por consensos $e$ entendimentos mútuos. Esse movimento crítico do campo da Administração, em especial dos estudiosos da teoria organizacional, fica estampado em obras como Teoria crítica nas organizaçôes, de Ana Paula Paes de Paula (2008), Tem razão a administração: ensaios de teoria organizacional (TENÓRIO, 2016a) e Uma alternativa: gestão social (TENÓRIO, 2016b), além de uma série de artigos publicados em periódicos relevantes da área. São significativos os artigos $A$ teoria da ação comunicativa de Habermas e suas aplicações nas organizações: contribuições para uma agenda de pesquisa 
(VASCONCELOS, PESQUEUX \& CIRINO, 2014), Ação comunicativa e estudos organizacionais (VIZEU, 2005) e Razão instrumental versus razão comunicativa (OLIVEIRA, 1993).

Cançado, Tenório e Pereira (2011) abordam o esgotamento das teorias administrativas tradicionais, amplamente criticada por pensadores brasileiros como Guerreiro Ramos, Maurício Tragtenberg e Prestes Motta. Os referidos autores enfatizam a força que a presença da literatura anglo-saxônica expressa na difusão e reprodução de uma formação em Administração calcada nos princípios $e$ técnicas do taylorismo-fordismo.

No Brasil, especialmente nos cursos de Administração, vamos absorvendo $e$ retransmitindo este conhecimento monológico anglo-saxônico em disciplinas como a Teoria Geral da Administração com seus Best Sellers. Os alunos dos primeiros períodos na graduação 'absorvem' este conhecimento e podem passar a acreditar que a Administração é praticamente uma ciência exata: diagnóstico-prescrição-solução.

(CANÇADO, TENÓRIO \& PEREIRA, 2011, p. 682)

Pode-se argumentar, a partir do ponto de vista da teoria habermasiana, que a "comunicação", ou seja, o conteúdo transmitido na forma de conhecimento sedimentado e com força de legitimidade científica, presente nos livros didáticos, periódicos científicos e mesmo revistas de ampla circulação entre estudantes (do nível superior e também do nível técnico) e profissionais da administração está profundamente alinhado à concepção tradicional de ciência (leia-se positivista), sendo, portanto, porta-voz dos postulados funcionalistas do taylorismo $e$ das posteriores escolas de pensamento administrativo que permanecem ancoradas no compromisso com a racionalidade empresarial e sua acumulação de capital $e$ não com as necessidades humanas efetivas, com a emancipação dos sujeitos e com o bem comum de uma sociedade autônoma $e$ democrática. Segundo comenta Siebeneichler (1989), caberia à filosofia, pela via habermasiana da interação e pelo paradigma da comunicação, a dupla tarefa de desobstruir o caminho da emancipação $e$ reconstruir simultaneamente o que foi reprimido na história do sujeito $e$ da sociedade. Isso implica, em relação à primeira tarefa, descortinar e expor aquilo que reprime ou distorce o diálogo e a comunicação por meio de uma crítica da ideologia positivista, tecnocrática $e$ funcionalista $e$, em relação à segunda tarefa, resgatar o interesse fundamental em emancipação e maioridade.

Número 29: nov./2017-abr./2018 
Essa abordagem alternativa do campo da Teoria das Organizações (TO) está fundamentada, principalmente, na Teoria do Agir Comunicativo (HABERMAS, 2012a; HABERMAS, 2012b), daí derivando-se a noção de "gestão social", uma posição antitética em relação à "gestão estratégica" (teorias administrativas tradicionais). Nas palavras de Tenório (2016b, p. 29, destaque do original):

No processo de gestão social, acorde com o agir comunicativo - dialógico, a verdade só existe se todos os participantes da ação social admitem sua validade, isto é, verdade é a promessa de consenso racional, ou a verdade não é uma relação entre o indivíduo $e$ a sua percepção do mundo, mas sim um acordo alcançado por meio da discussão crítica, da apreciação intersubjetiva.

A TAC de Habermas, ao ser pensada no campo da TO, pode trazer contribuições significativas especialmente por carregar consigo uma proposta de compreensão racional da ação social. É devido a isso que o próprio autor julga ser a TAC "uma mudança de paradigma social" (HABERMAS, 2012a, p. 629), dado sua proposta apresentar um "novo paradigma da razão" (HABERMAS, 2012a, p. 672) ao qual está associado o abandono do agir orientado por fins (WEBER, 1999) passando-se ao agir comunicativo. Nesse sentido, a gestão social também poderia ser compreendida como uma forma de administrar colocando em foco a razão comunicativa, distintamente da administração tradicional em que prevalece a razão instrumental ou estratégica. Isso implica em diversas mudanças de postura em termos de distribuição do poder decisório, cultura organizacional, processo de tomada de decisão, elaboração de planejamento estratégico organizacional, estabelecimento de objetivos e metas, sistemas de acompanhamento e avaliação por meio de indicadores, os quais não deixariam de existir, mas seriam reinterpretados por outra lógica.

\footnotetext{
Entenderemos gestão social como o processo gerencial dialógico em que a autoridade decisória é compartilhada entre os participantes da ação (ação que possa ocorrer em qualquer tipo de sistema social - público, privado ou de Organizações Não Governamentais). O adjetivo social qualificando o substantivo gestão será entendido como o espaço privilegiado de relações sociais no qual todos têm o direito à fala, sem nenhum tipo de coação. (TENÓRIO, 2016b, p. 42, destaques do original)
}

A noção de "gestão social", concebida a partir da TAC habermasiana, poderia ser interpretada como uma tentativa de trazer as questões inerentes ao mundo da vida presentes na vida social dentro das organizações para serem problematizadas por uma nova forma de 
administrar, a saber, pela via do diálogo racional $e$ da busca por soluções e de processos de tomada de decisão realizados consensualmente. Jürgen Habermas aborda o processo de colonização do "mundo da vida" pelo "sistema", especialmente nas obras Teoria do agir comunicativo (HABERMAS 2012a; HABERMAS 2012b) e $O$ discurso filosófico da modernidade (HABERMAS, 2000). O mundo da vida é o locus par excellence da razão comunicativa em termos habermasianos. Ele é constituído pela cultura, sociedade e personalidade $e$ está fundado sobre a busca de consensos entre os indivíduos, por intermédio do diálogo intersubjetivo. Ele se contrapõe de modo antitético ao "sistema", locus da razão cognitivo-instrumental, expressa nas ações teleológicas dos indivíduos que buscam o êxito em suas ações para alcançar determinados fins previamente selecionados. O sistema expressa a razão do dinheiro $e$ do poder $e$, sendo assim, se impõe aos indivíduos como pesado manto cultural que exige contínua adaptação. Essa racionalidade se configura tanto na forma da economia capitalista, de modo amplo, como na burocracia administrativa, como discute Weber (1999; 1958) e é retomado nas mencionadas obras de Jürgen Habermas.
Se aceitarmos a hipótese de que haveria a oportunidade de criação de espaços de discussão, deliberação e tomada de decisões por parte dos trabalhadores nas organizações pós-fordistas no cenário que sucede, no Brasil, a redemocratização do país, a promulgação da Constituição Federal de 1988 e a promulgação da nova Lei de Diretrizes e Bases da Educação Nacional (Lei n. 9394/96) - nas quais está assentado o princípio da gestão democrática -, à luz do entendimento da TAC de Habermas, então a formação educacional e profissional formal dos trabalhadores nas escolas, analogamente, poderia incorporar as dimensões cultural $e$ política na concepção de educação, na elaboração da proposta pedagógica e dos currículos. Se a ciência e a técnica são portadoras da capacidade de produzir "poder de disposição", como argumenta Habermas (2013), empoderando os homens ao domínio técnico, porém sem a compreensão crítica do mesmo poder de disposição técnica, então caberia ao processo formativo colocar em estado de suspeição as funções sociais $e$ finalidades da ciência e da técnica. Conforme aponta o filósofo,

Atualmente, os processos de investigação científica são acoplados com a aplicação 
técnica e a valorização econômica, e a ciência é acoplada com a produção e a administração no sistema de trabalho de sociedades industrializadas: a aplicação da ciência à técnica e a reutilização dos progressos técnicos na investigação científica se tornaram a própria substância do mundo do trabalho. [...] A forma universitária do estudo não deve se proteger hoje contra as esferas profissionais porque estas seriam alheias à ciência, mas porque, pelo contrário, a ciência, na medida em que ela impregnou a prática profissional, tornou-se alheia por sua vez à formação. (HABERMAS, 2013, p. 546)

A abordagem de Habermas é esclarecedora entre a relação entre ciência/técnica e produção e sua administração: uma relação dialógica na qual há uma nítida dependência da esfera produtiva em relação aos progressos técnico-científicos, assim como simultaneamente $\mathrm{o}$ trabalho $e$ sua organização se tornam cada vez mais cientifizados e tecnificados, ou seja, instrumentalizados, sendo a forma de administrar (ou controlar) parte inerente dessa realidade.

[...] o crescimento relativo das forças produtivas não representa mais eo ipso um potencial transbordante $e$ rico em consequências emancipatórias, que pudesse romper as legitimações de uma ordem de dominação existente. Pois, desde agora, a principal força produtiva, o próprio progresso técnico-científico assimilado à administração, tronou-se fundamento da legitimação. Essa nova forma de legitimação perdeu contudo a antiga figura de ideologia. (HABERMAS, 1983, p. 335)
O problema é que o poder de disposição proporcionado pela ciência (e pela técnica) não carregaria consigo potenciais emancipatórios já que se distanciou das reais necessidades humanas como finalidade. $\mathrm{O}$ mesmo raciocínio cabe à Administração e à Administração da Educação enquanto campos de conhecimento sistematizados. Para Habermas, o poder de disposição não é a mesma coisa que o poder prático (poder da vida e da ação, potencial da ação esclarecida) voltado à solução das questões de fundo de ordem prática do ser humano. Conforme argumenta o filósofo em relação à formação,

\begin{abstract}
[...] é certo que nossos estudantes, ao serem instruídos nos procedimentos de uma ciência positiva, recebem logo informações tecnicamente indispensáveis sobre processos que devem ser dominados, mas nenhuma orientação que auxilie nas situações práticas da vida. (HABERMAS, 2013, p. 547)
\end{abstract}

As questões práticas são aquelas relacionadas ao mundo da vida, não ao sistema, devido a isso a argumentação do filósofo sobre a necessidade de haver uma formação simultaneamente técnica $e$ política, tendo na ciência o aporte da capacidade de reflexão autônoma e crítica. Antes de tudo, porém, ele indica uma 
premissa fundamental, a saber, que essa ciência seja capaz de autorreflexão. Para o autor:

Hoje, a investigação científica compete a uma dupla função do ensino: primeiro, a mediação do saber formal e do empírico para o aperfeiçoamento nas técnicas profissionais e no próprio processo de investigação científica; mas, também, àquela retradução de resultados científicos no horizonte do mundo da vida, que permitiria introduzir o conteúdo informativo das recomendações técnicas nas discussões sobre o que é considerado necessário em termos práticos da perspectiva do interesse universal. [...] Não se trata de incorporar o estágio de saber cheio de consequências práticas no poder de disposição dos homens que executam tarefas técnicas, mas de recuperá-lo na posse linguística da sociedade constituída pela comunicação. Hoje, essa é a tarefa de uma formação acadêmica, que tanto hoje quanto antes precisa ser assumida por uma ciência capaz de autorreflexão. (HABERMAS, 2013, p. 561, grifos nossos)

Verifica-se assim a efetiva articulação entre educação e trabalho, ambos permeados pela ciência na abordagem habermasiana. Dessa tessitura teórico-epistemológica há possibilidades emergentes de abordagem tanto na esfera da produção e do trabalho, quanto da Educação Profissional, objeto central de nossas pesquisas atuais, costuradas pela teoria do agir comunicativo. Uma possível Administração Educacional Dialógica (AED) operaria não apenas com uma perspectiva distinta da administração burocrática ou estratégica, como seria capaz de realizar uma perene autorreflexão sobre si mesma. Isso está em harmonia com a compreensão de que todo ato administrativo nas escolas é simultaneamente um ato pedagógico, exigindo atenção especial aqueles elementos constitutivos do mundo da vida inerentes ao lócus escolar enquanto espaço de formação humana.

A elaboração de uma concepção de Administração Educacional Dialógica está alicerçada em dois aportes, um da Filosofia - a TAC de Habermas - e outro da Administração (ou mais precisamente da área de Teoria Crítica das Organizações) - a gestão social. Os elementos basilares a constituir essa hipotética noção de administração ou gestão educacional são a dialogicidade, o entendimento, a transparência e a tomada de decisão livre de coação.

Uma gestão educacional dialógica e, portanto, crítica - seria orientada por valores como cooperação (no lugar da competição), autonomia e emancipação (ao invés de mera adaptação do sujeito/heteronomia), geração de potencial de ação esclarecida (e não somente de disposição técnica, mas sem abandoná-la) e valorização dos aspectos políticos e culturais (e não somente dos aspectos técnicos). 
Pensando-se especificamente na escola da Educação Profissional como lócus de formação humana plena - para o trabalho $e$ para todas as demais dimensões da vida social $-e$ na prerrogativa constitucional $e$ presente na nova LDB de 1996 do princípio da gestão democrática, justifica-se o trabalho de pesquisa na elaboração de uma concepção de administração educacional dialógica, na qual haja um ambiente propício à participação de todos os atores sociais do espaço escolar, sem restrições $e$ coações. A escola deveria se constituir em lócus privilegiado para uma gestão baseada na comunicação livre de constrangimentos, na qual todos podem apresentar seus argumentos com pretensões de validade $e$ procurar justificá-los racionalmente. Habermas faz uma interessante análise na qual relaciona a capacidade de argumentação, a possibilidade de corrigir erros e o processo de aprendizado que há nisso, imprescindíveis a esta concepção de administração:

Exteriorizações racionais, em virtude da possibilidade de serem criticadas, são também passíveis de correção: podemos corrigir tentativas malsucedidas quando logramos identificar os erros que nos tenham passado despercebidos. $\mathrm{O}$ conceito de fundamentação está intimamente ligado ao de aprendizado. Também no caso dos processos de aprendizado a argumentação desempenha um papel importante. (HABERMAS, 2012, p. 49)

Essas considerações sobre a Administração Educacional Crítica, ainda preliminares, indicam um frutífero campo de pesquisa, já que a própria "gestão social" é considerada por seu idealizador $e$ por pesquisadores aderentes a ela como um campo em construção. Isso possibilita anunciar uma agenda de pesquisa com as seguintes ações: i) estudar o campo da Teoria Crítica das Organizações (TCO); ii) investigar as potenciais contribuições da Escola de Frankfurt ao campo da TCO; iii) aprofundar a pesquisa sistemática sobre as contribuições adicionais da TAC de Jürgen Habermas à elaboração e formalização de uma concepção de Administração Educacional Crítica.

O Quadro 1 apresenta os principais contrastes que poderíamos indicar, nesta perspectiva ainda embrionária, entre a Administração Educacional Dialógica e a Administração Educacional Tradicional. 
apontam para o fato histórico de que houve um processo de mimetização e assimilação

Quadro 1 - Elementos constitutivos da Administração Educacional Dialógica

\begin{tabular}{|c|c|c|}
\hline Aspectos & $\begin{array}{c}\text { Administração Educacio- } \\
\text { nal Tradicional }\end{array}$ & $\begin{array}{l}\text { Administração Educa- } \\
\text { cional Dialógica }\end{array}$ \\
\hline Tipo de racionalidade & Razão instrumental & Razão comunicativa \\
\hline Dimensão hegemônica & Sistema & Mundo da vida \\
\hline Comunicação & Monológica & Dialógica \\
\hline Tomada de decisão & Diretiva (individual) & Democrática (coletiva) \\
\hline Autoridade/poder & Hierárquica (vertical) & Igualitária (horizontal) \\
\hline $\begin{array}{l}\text { Percepção sobre os ato- } \\
\text { res }\end{array}$ & Sujeito individual & Sujeito social \\
\hline Horizonte de alcance & Interesses subjetivos & Interesses coletivos \\
\hline $\begin{array}{l}\text { Posicionamento do indi- } \\
\text { víduo na socieda- } \\
\text { de/grupo }\end{array}$ & Competição & Cooperação \\
\hline Tecnologias de gestão & $\begin{array}{l}\text { Poder de disposição téc- } \\
\text { nica (controle e coman- } \\
\text { do) }\end{array}$ & $\begin{array}{c}\text { Potencial de ação es- } \\
\text { clarecida (deliberação e } \\
\text { orientação) }\end{array}$ \\
\hline Aspectos relevantes & Técnicos & $\begin{array}{c}\text { Técnicos, políticos e } \\
\text { culturais }\end{array}$ \\
\hline $\begin{array}{l}\text { Objetivos das ações de } \\
\text { gestão }\end{array}$ & $\begin{array}{l}\text { Melhoria dos processos } \\
\text { do sistema educacional }\end{array}$ & $\begin{array}{c}\text { Melhoria dos processos } \\
\text { formativos }\end{array}$ \\
\hline $\begin{array}{l}\text { Objetivo último da edu- } \\
\text { cação }\end{array}$ & $\begin{array}{l}\text { Adaptação do sujeito ao } \\
\text { sistema social e mercado }\end{array}$ & $\begin{array}{l}\text { Autonomia e emanci- } \\
\text { pação + poder de dis- } \\
\text { posição esclarecido }\end{array}$ \\
\hline
\end{tabular}

Fonte: elaboração própria.

\section{Considerações finais}

A pretensão deste artigo foi apresentar ao leitor a possibilidade de colocar em estado de suspeição o emprego dos conteúdos teóricos e práticos da Administração empresarial de forma acrítica e sem adaptações à gestão de escolas $e$ sistemas escolares. Diversos pesquisadores do campo da política e gestão educacional das teorias administrativas empresariais, desde o início do século $\mathrm{XX}$, ao nascente campo da Administração e Organização Escolar. Gerir as escolas de modo análogo ao que se faz numa fábrica ou escritório comercial é incorrer em constrangimentos sérios à plena formação humana em todos os sentidos para além da pura instrumentalização do estudante em termos de conteúdos curriculares. 


\begin{abstract}
Vimos que mesmo entre os pesquisadores do próprio campo de conhecimento da Administração há considerável parcela que questiona os princípios, teorias e normatizações de caráter pragmático e funcionalista aplicados às organizações. Essa fração da academia olha com desconfiança para a Administração enquanto ciência positivista com pretensões de imitação das ciências naturais e, além disso, critica a ausência de preocupações com os aspectos culturais, políticos e sociais envolvidos na gestão $e$ coordenação das atividades de produção de bens e serviços que ocorrem no interior das organizações.
\end{abstract}

A gestão social, fundada na teoria do agir comunicativo de Jürgen Habermas, apresenta-se como alternativa à administração tradicional. Não se trata de abdicar dos saberes, das técnicas, enfim do conjunto de conhecimento desenvolvido por esta última, mas sim de colocá-los à disposição da finalidade a que se deveriam se destinar as organizações em geral: a produção de bem-estar ao homem. Quando miramos o foco da análise para a escola, em particular para a Educação Profissional, vislumbram-se possibilidades de se pensar numa Administração e em políticas educacionais capazes de proporcionar uma formação plena de sujeitos emancipados, autônomos, preparados para a vida e para o trabalho, plenos de disposição técnica, mas também capazes de ação esclarecida. É nessa orientação que se coloca a agenda de pesquisa apresentada, a qual nos parece bastante fecunda e coerente com os propósitos da Teoria Crítica da Sociedade.

\section{Referências}

BRAVERMAN, Harry. Trabalho e capital monopolista: a degradação do trabalho no século XX. Tradução de Nathanael C. Caixeiro. 3 ed. Rio de Janeiro: Zahar Editores, 1980. (Biblioteca de Ciências Sociais: Sociologia e Antropologia).

CANÇADO, Airton Cardoso; TENÓRIO, Fernando Guilherme; PEREIRA, José Roberto. Gestão social: reflexões teóricas e conceituais. CADERNOS EBAPE.BR., v. 9, n.3, artigo 1, Rio de Janeiro, set. 2011, p. 681-703.

CURY, Carlos Roberto Jamil. Gestão democrática da educação: exigências e desafios. Revista Brasileira de Política e Administração da Educação, v. 18, n.2, juldez. 2002, p. 163-174.

GRUSCHKA, Andreas. Escola, didática e indústria cultural. In: DURÃO, Fabio Akcelrud; ZUIN, Antonio; VAZ, Alexandre Fernandez (org.). A indústria cultural hoje. São Paulo: Boitempo, 2008.

HABERMAS, Jürgen. Teoria e práxis: estudos de filosofia social. São Paulo: Editora Unesp, 2013. 
Teoria do agir comunicativo: racionalidade da ação e racionalização social. São Paulo: WMF Martins Fontes, 2012a. vol. 1.

Teoria do agir comunicativo: sobre a crítica da razão funcionalista. São Paulo: WMF Martins Fontes, 2012b. vol. 2.

. O discurso filosófico da modernidade: doze lições. São Paulo: Martins Fontes, 2000. (Coleção tópicos).

- Técnica e ciência enquanto "ideologia". In: BENJAMIN, Walter; HORKHEIMER, Max; ADORNO, Theodor W.; HABERMAS, Jürgen. Textos escolhidos. São Paulo: Abril Cultural, 1983. (Os Pensadores).

KUENZER ZUNG, Acácia Zeneida. A teoria da administração educacional: ciência $e$ ideologia. Cadernos de Pesquisa, São Paulo (48), fev. 1984, p. 39-46.

MAIA, Graziela Zambão Abdian. As publicações da ANPAE e a trajetória do conhecimento em administração da educação no Brasil. Revista Brasileira de Política e Administração da Educação, v. 24, n.1, jan./abr. 2008, p.31-50.

OLIVEIRA, Fátima Bayma de. Razão instrumental versus razão comunicativa. Revista de Administração Pública, 27 (3), Rio de Janeiro, jul./set. 1993, p. 15-25.

PAULA, Ana Paula Paes de. Teoria crítica nas organizações. São Paulo: Thomson Learning, 2008. (Coleção debates em administração).

RODRIGUES, José. O moderno príncipe industrial: o pensamento pedagógico da Confederação Nacional da Indústria.
Campinas: Autores Associados, 1998. (Educação Contemporânea).

SANDER, Benno. Administração da educação no Brasil: genealogia do conhecimento. Brasilia-DF: Liber Livro, 2007.

Políticas públicas e gestáo democrática da educação. Brasília, DF: Lỉber Livro, 2005.

SIEBENEICHLER, Flávio Benno. Jürgen Habermas: razão comunicativa $e$ emancipação. Rio de Janeiro: Tempo Brasileiro, 1989.

TENÓRIO, Fernando Guilherme. Tem razão a administração? Ensaios de teoria organizacional. 4 ed. rev. e ampl. Ijuí-RS: Editora Unijuí, 2016a.

. Uma alternativa: gestão social. IjuíRS: Editora Unijuí, 2016b.

TRAGTENBERG, Maurício. Burocracia e ideologia. 2 ed. rev. São Paulo: Editora UNESP, 2006. (Coleção Maurício Tragtenberg).

VARGAS, Nilton. Gênese e difusão do taylorismo no Brasil. Ciências Sociais Hoje. São Paulo: ANPOCS, 1985, p. 155-190.

VASCONCELOS, Isabella Francisca Freitas Gouveia de; PESQUEUX, Yvon; CYRINO, Alvaro Bruno. A Teoria da Ação Comunicativa de Habermas e suas aplicações nas organizações: contribuições para uma agenda de pesquisa. CADERNOS EBAPE.BR., v. 12, edição especial, Rio de Janeiro, ago. 2014, p. 374-383.

VIZEU, Fábio. Ação comunicativa e estudos organizacionais. Revista de Administração 
de Empresas - RAE, v. 45, n. 4, out./dez. 2005, p. 10-21.

WEBER, Max. Historia económica general. $8^{a}$ reimpressão. Tradução de Manuel Sánchez Sarto. México: Fondo de Cultura Económica, 2001.

Economia e sociedade: fundamentos da sociologia compreensiva. Brasília, DF: Editora da Universidade de Brasília/São Paulo: Imprensa Oficial do Estado de São Paulo, 1999. vol. 1.

- From Max Weber: essays in sociology. New York: Oxford University Press, 1958. Translated, edited, and with an introduction by $\mathrm{HH}$. Gerth and C. Wright Mills.

Recebido em: 09/03/2018

Aprovado em: 10/04/2018 